\title{
Fabrication and Catalytic Decoloration Capacity of Nanodendritic Metals
}

\author{
Masataka Hakamada, Takayuki Matsuzawa* and Mamoru Mabuchi \\ Department of Energy Science and Technology, Graduate School of Energy Science, Kyoto University, Kyoto 606-8501, Japan
}

Nanodendritic Pd was fabricated by square-wave potential pulse (SWPP) electrolysis on Pd surface. Dendrite cell sizes and dendrite arm spacings were well below $100 \mathrm{~nm}$ and decreased with the increase in the frequency of SWPP. Cyclic voltammetry revealed that true surface area of Pd increased by up to 57 times by the nanodendritic structure. Nanodendritic Au was also fabricated by SWPP and its catalytic decoloration capacity was compared with that of nanoporous Au. Nanodendritic Au decomposed methyl orange more efficiently than nanoporous Au. This may be attributed to high-index facets and edges commonly found in nanodendritic structures synthesized by SWPP electrolysis. [doi:10.2320/matertrans.MBW201310]

(Received October 15, 2013; Accepted November 20, 2013; Published December 28, 2013)

Keywords: dendrite, square-wave potential pulse, gold, palladium, catalyst, decoloration, high-index facet, edge

\section{Introduction}

Various metallic nanomaterials with typical length scale in the order of nanometers, such as metallic nanoparticles, ${ }^{1)}$ nanowires $^{2)}$ and nanorods ${ }^{3)}$ are being fabricated because of their specific properties due to the quantum and/or surface effects. Among others, nanoparticles of noble metals such as $\mathrm{Au}$ and $\mathrm{Pt}$ are readily prepared by impregnation techniques, which generally require compounds such as $\mathrm{HAuCl}_{4}$ and $\mathrm{H}_{2} \mathrm{PtCl}_{6}$ as starting materials. ${ }^{1,4)}$ On the other hand, noble metals are mostly produced in the elemental form, not chemical compounds, in nature, and thus, in noble metal mines. If noble metals are directly converted to metallic nanomaterials, not through the formation of compounds, energy and cost may be saved.

When the square-wave potential pulse (SWPP) is applied to metal electrodes in an electrolyte, dendritic structure evolves on the electrode surface through repetitions of tiny dissolution and re-deposition of the electrode material. ${ }^{5-8)}$ Under some conditions, nanodendritic structures, that is, dendrite forests with dendrite cell size and dendrite arm spacings in the order of nanometers, can be obtained. Fabrication by SWPP electrolysis needs no chemical compounds of noble metals and can still be attained at room temperature and ambient atmosphere. Thus SWPP electrolysis is one of the promising methods for fabrication of metallic nanomaterials.

SWPP electrolysis has been mainly reported as for $\mathrm{Au}$ and $\mathrm{Pt}$; however, less is remarked as for Pd. Hence, the fabrication condition of nanodendritic Pd with high surface area was investigated in this study. Also, catalytic properties of nanodendritic Au synthesized by SWPP electrolysis were evaluated using degradation of an azo dye (decoloration) as a probe reaction.

\section{Experimental}

\subsection{SWPP electrolysis for fabrication of nanodendritic Pd and Au}

A typical three-electrode electrochemical cell with $\mathrm{Ag}|\mathrm{AgCl}|$ sat. $\mathrm{KCl}$ reference electrode $(+0.196 \mathrm{~V}$ vs. standard

*Graduate Student, Kyoto University

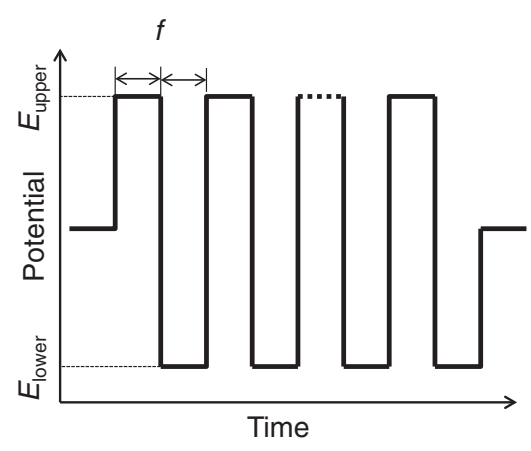

Fig. 1 Schematic diagram for square-wave potential pulse method to fabricate nanodendritic metals.

hydrogen electrode) and Pt counter electrode was used for the preparation of nanodendritic metals by SWPP electrolysis. In this paper, potentials will be documented based on $\mathrm{Ag}|\mathrm{AgCl}|$ sat. $\mathrm{KCl}$ electrode. The $\mathrm{Pd}(>99.90 \%)$ and $\mathrm{Au}$ (>99.99\%) (Tanaka Kikinzoku, Japan) plate was polished to a mirror-like finish, washed by distilled water and ethanol, and used as working electrodes. Areas of $3 \mathrm{~mm} \times 3 \mathrm{~mm}$ of the working electrodes were exposed to the electrolyte ( $1 \mathrm{~mol} / \mathrm{L} \mathrm{H}_{2} \mathrm{SO}_{4}$ ). SWPP was conducted by applying the alternating potential (Fig. 1) to the working electrode. Upper and lower potentials ( $E_{\text {upper }}$ and $E_{\text {lower }}$ ) were set to +6.0 and $-5.0 \mathrm{~V}$, respectively, and electrolysis time was $15 \mathrm{~min}$ for $\mathrm{Pd}$. As for $\mathrm{Au}, E_{\text {upper }}$ was $+1.1 \mathrm{~V}, E_{\text {lower }}$ was $-1.2 \mathrm{~V}$ and electrolysis time was $60 \mathrm{~min}$. Frequency $(f)$ of square-wave oscillation was set to 50,100 and $200 \mathrm{~Hz}$ for Pd, while set to $50 \mathrm{~Hz}$ for $\mathrm{Au}$.

After the electrolysis, the surface area of the sample (working electrode) was evaluated by cyclic voltammetry $(\mathrm{CV})$ in $0.5 \mathrm{~mol} / \mathrm{L} \mathrm{H}_{2} \mathrm{SO}_{4}$ in the same electrochemical cell with scan rate of $100 \mathrm{mV} / \mathrm{s}^{9)}$ All electrochemical operation was conducted at $298 \mathrm{~K}$. Surface microstructures were observed by a scanning electron microscope (S-4300, Hitachi High-Technology, Japan) with an energy-dispersive X-ray (EDX) spectrometer (XFlash 5010, Bruker AXS, Germany).

\subsection{Decoloration capacity of nanodendritic Au}

Methyl orange, a typical azo used in the textile industry, is stable and is commonly used as the probe for evaluating 
photocatalysts; ${ }^{10,11)}$ thus the catalytic activities of the nanodendritic $\mathrm{Au}$ for degradation of methyl orange was assessed at 298 K. Nanodendritic Au fabricated by SWPP electrolysis was immersed into $5 \mathrm{~mL}$ of methyl orange aqueous solution $\left(2 \times 10^{-5} \mathrm{~mol} / \mathrm{L}\right)$. The experiments were conducted under a dark condition to distinguish the methyl orange decrease from photocatalysis. The concentration of methyl orange in the solution as a function of soaking time was measured by monitoring the absorbance of the methyl orange at its absorption maximum wavelength $\left(\lambda_{\max }=466.5 \mathrm{~nm}\right)$ using a UV-Vis spectrometer (UV-2100 Shimadzu, Japan). For comparison with the decoloration by nanoporous $\mathrm{Au},{ }^{12}$ ) reacted amount of methyl orange was normalized by the surface area of the nanodendritic and nanoporous $\mathrm{Au}$, which was estimated by the CV measurements.

\section{Results and Discussion}

\subsection{Fabrication of nanodendritic Pd}

After SWPP electrolysis, the surface of Pd working electrode turned black and lost its mirror-like luster, suggesting the formation of rough structure. Figure 2(a) shows the SEM image of the surface of Pd working electrode after SWPP electrolysis with $f=100 \mathrm{~Hz}$. Dendritic structure was observed all over the surface exposed to the electrolyte. Dendrite arm thickness and spacing were much smaller than $100 \mathrm{~nm}$. As shown in Fig. 2(b), EDX spectrum for the surface exhibited only $\mathrm{Pd}$. No possible contaminant elements such as sulfur and oxygen (from $\mathrm{H}_{2} \mathrm{SO}_{4}$ electrolyte) were detected. Thus, nanodendritic elemental $\mathrm{Pd}$ can be fabricated by SWPP electrolysis.

Figure 3 shows the $\mathrm{CV}$ curve for nanodendritic Pd samples with $f=200 \mathrm{~Hz}$. For comparison, the curve for flat Pd with smooth surface is also shown. It can be seen that the current magnitude for nanodendritic Pd wire is much higher than that for flat Pd. The enhancement of current magnitude is attributed to the nanodendritic structure induced by the SWPP electrolysis.

Roughness factor $(R)$, that is, the ratio of true surface area to apparent surface area, can be estimated by the CV curves. Electrochemically active surface area $(A)$ can be estimated using the charge associated with the reduction of adsorbed oxygen $^{9)}$ and converted to $R$ by the following equation:

$$
R=A_{\text {nd }} / A_{\text {flat }}=Q_{\text {oC,nd }} / Q_{\text {oc,flat }}
$$

where $Q_{\mathrm{OC}}$ is the charge associated with the reduction of adsorbed oxygen. Subscript "nd" and "flat" mean that the variables are for the nanodendritic and flat $\mathrm{Pd}$, respectively. $Q_{\mathrm{OC}}$ can be calculated using the cathodic peak between +0.3 and $+0.7 \mathrm{~V}$ after correction for double layer charging. Calculated $R$ for the sample with $f=200 \mathrm{~Hz}$ is 57 ; that is, the true surface area of nanodendritic $\mathrm{Pd}$ wire is 57 times larger than that of flat Pd on the assumption that the reduction of adsorbed oxygen is not affected by specific shapes of nanodendrites.

Figure 4 shows the SEM images of nanodedritic $\mathrm{Pd}$ fabricated by SWPP electrolysis with $f=50,100$ and $200 \mathrm{~Hz}$. As $f$ increased, dendrite cell size decreased. Needle-like dendrite arms (with high aspect ratio of length to thickness) were observed in the samples with $f=100$ and (a)

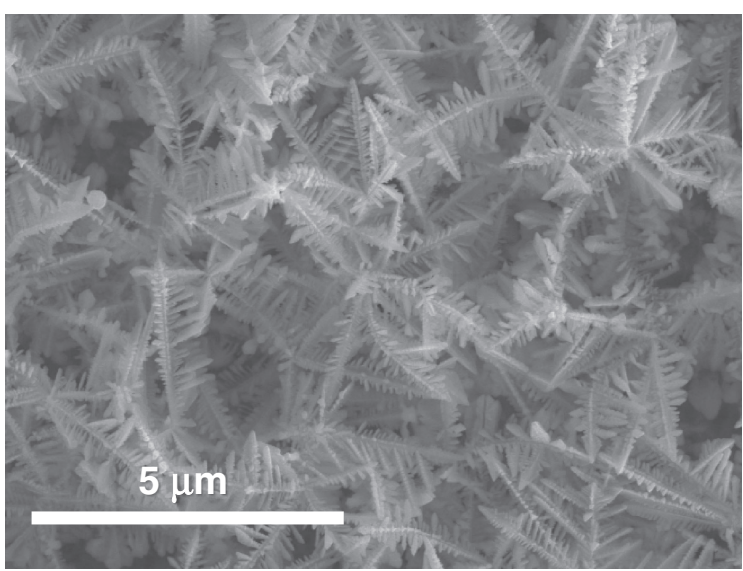

(b)

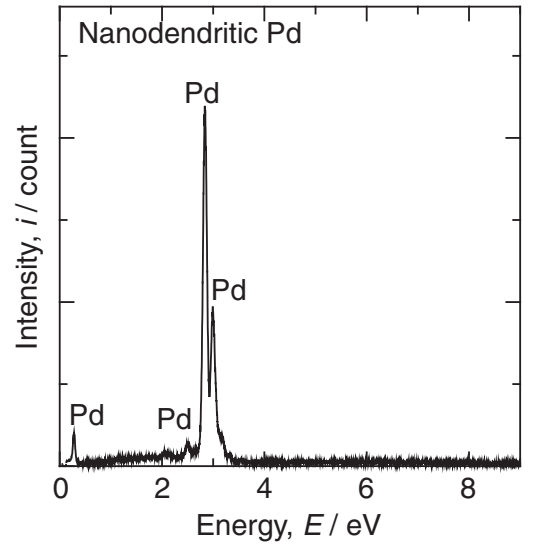

Fig. 2 SEM image of nanodendritic Pd fabricated by square-wave potential pulse method under condition of $E_{\text {upper }}=+6.0 \mathrm{~V}, E_{\text {lower }}=-5.0 \mathrm{~V}$ and $f=100 \mathrm{~Hz}$.

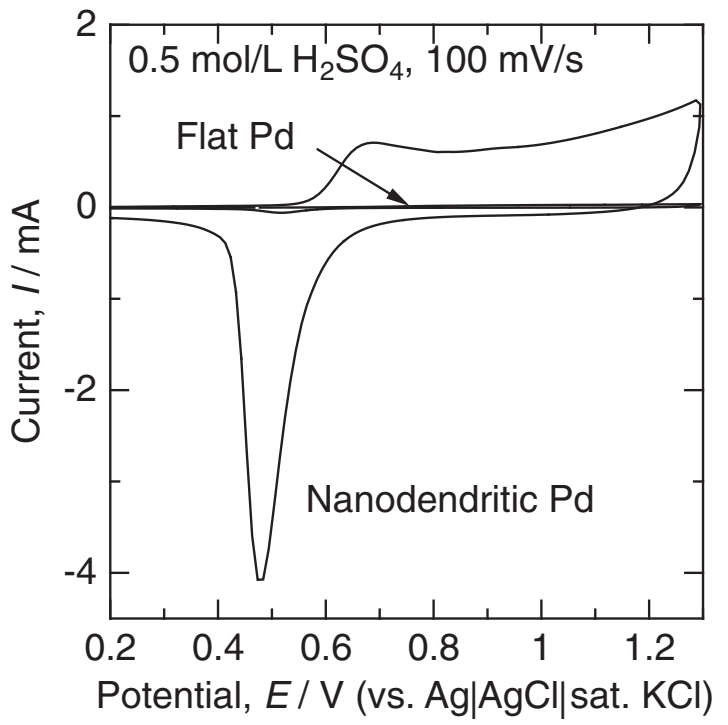

Fig. 3 Cyclic voltammetry curves for flat and nanodendritic Pd. Nanodendritic Pd was fabricated by the square-wave potential pulse method under condition of $E_{\text {upper }}=+6.0 \mathrm{~V}, E_{\text {lower }}=-5.0 \mathrm{~V}$ and $f=200 \mathrm{~Hz}$.

$200 \mathrm{~Hz}$ while granular cells consisted the nanodendritic Pd with $f=50 \mathrm{~Hz}$. Table 1 summarizes the size feature and roughness factor of nanodendritic Pd fabricated by SWPP electrolysis, where the size features were measured for more than 100 dendrite arms and cells by inspecting SEM observations. Higher frequency resulted in the reduction in 

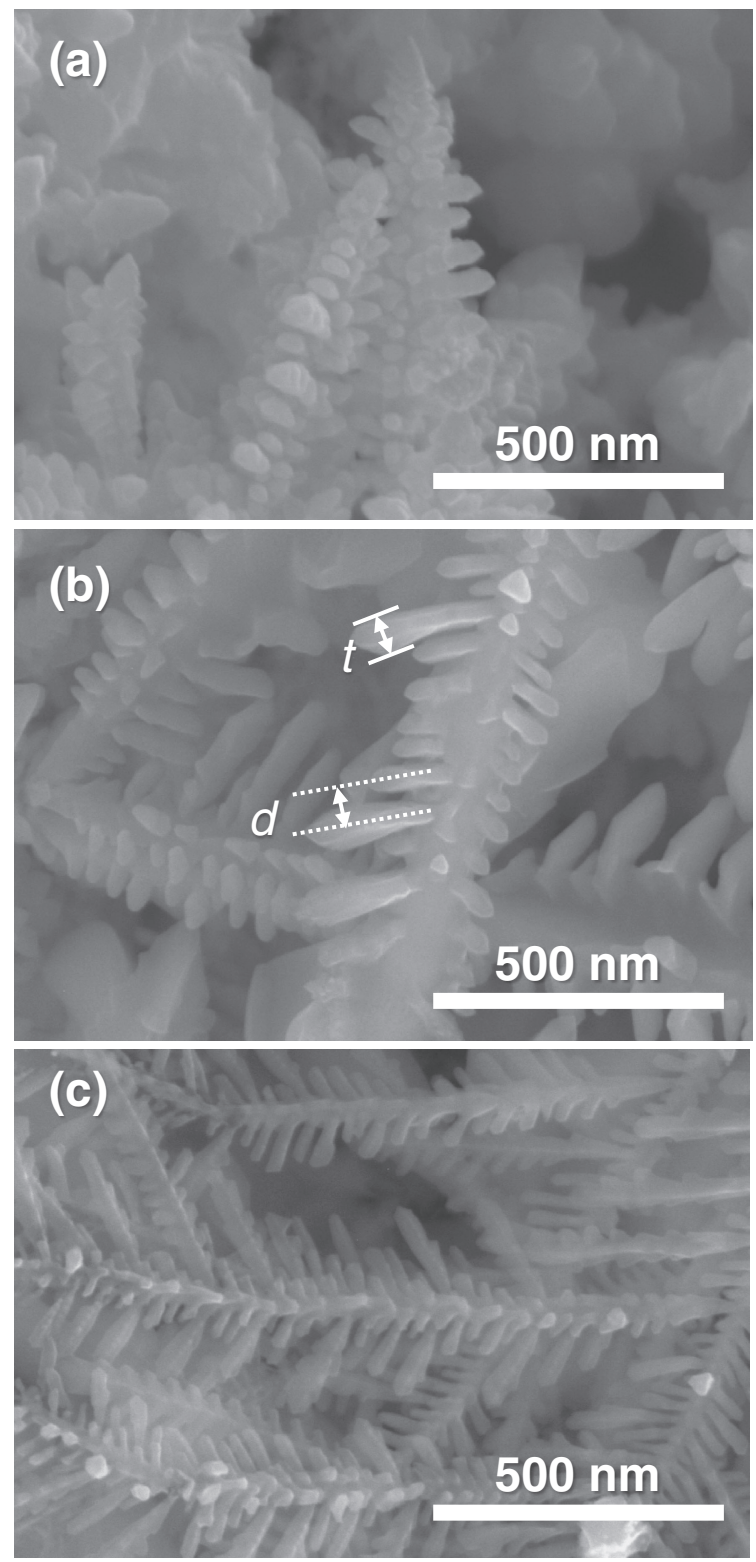

Fig. 4 SEM images of nanodendritic Pd fabricated by square-wave potential method under condition of $E_{\text {upper }}=+6.0 \mathrm{~V}, E_{\text {lower }}=-5.0 \mathrm{~V}$, $f=$ (a) 50, (b) 100 and (c) $200 \mathrm{~Hz}$. Dendrite cell size ( $t$ ) and dendrite arm spacing $(d)$ summarized in Table 1 are also schematically shown.

Table 1 Size feature and roughness factor of nanodendritic Pd fabricated by SWPP electrolysis with various frequencies.

\begin{tabular}{cccc}
\hline $\begin{array}{c}\text { Frequency, } \\
f / \mathrm{Hz}\end{array}$ & $\begin{array}{c}\text { Dendrite } \\
\text { cell size, } \\
t / \mathrm{nm}^{* 3}\end{array}$ & $\begin{array}{c}\text { Dendrite arm } \\
\text { spacing, } \\
d / \mathrm{nm}^{* 3}\end{array}$ & $\begin{array}{c}\text { Roughness } \\
\text { factor, } \\
R\end{array}$ \\
\hline 50 & $49 \pm 8$ & $45 \pm 9$ & 13 \\
100 & $44 \pm 12$ & $48 \pm 12$ & 18 \\
200 & $23 \pm 7$ & $28 \pm 5$ & 57 \\
\hline
\end{tabular}

${ }^{* 1}$ Maximum width of cell.

${ }^{* 2}$ Spacing between center lines of adjacent cells.

${ }^{* 3}$ Standard deviation is also shown.

the dendrite cell size and subsequent increase in effective surface area. Xia et al. reported that high frequency in SWPP electrolysis is required for the growth of nanodendritic $\mathrm{Au}{ }^{5)}$ Thus similarly, higher frequency in SWPP electrolysis is crucial for fabrication of well-grown nanodendritic $\mathrm{Pd}$ with
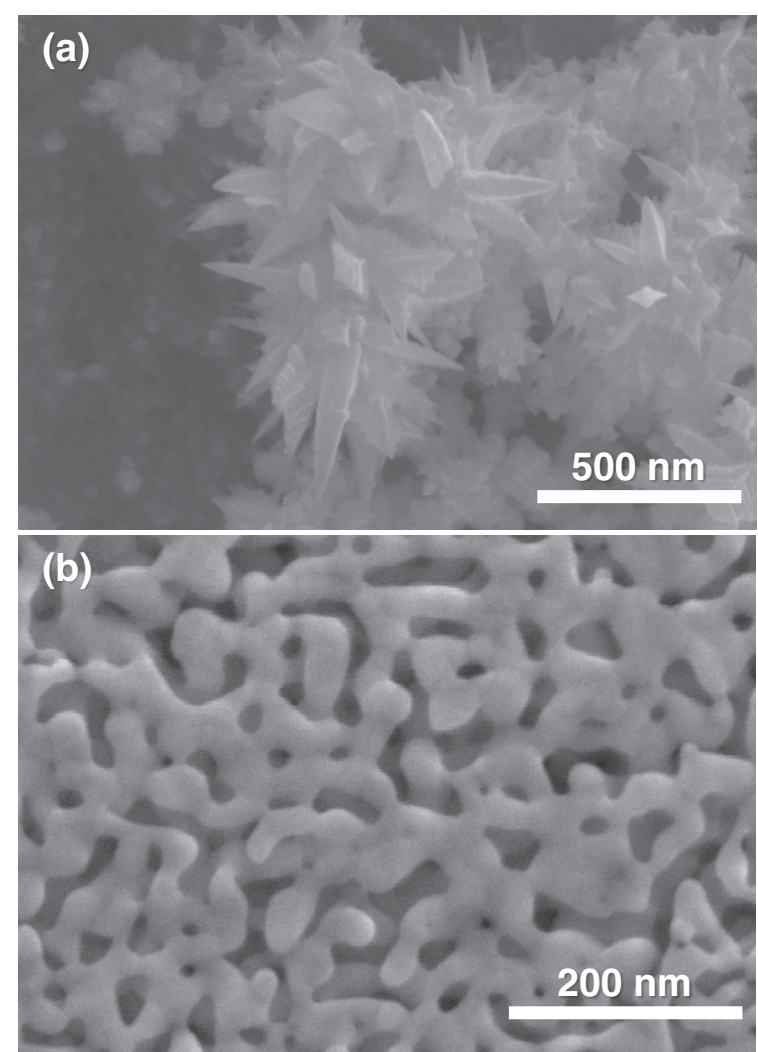

Fig. 5 SEM images of (a) nanodendritic Au fabricated by square-wave potential pulse method and (b) nanoporous Au fabricated by dealloying.

fine dendrite cell size. Repetition of tiny dissolution and redeposition of Pd seems responsible for the nanodendrite formation during SWPP electrolysis; higher frequency may offer many nucleation sites for dendrites, resulting in finer size feature.

Careful inspection of Table 1 reveals that dendrite arm spacings in the samples with $f=50$ and $100 \mathrm{~Hz}$ are similar, although roughness factor of the sample with $f=100 \mathrm{~Hz}$ was higher than that of the sample with $f=50 \mathrm{~Hz}$. The needle-like dendrite arms, rather than granular dendritic cells, may increase accessible surface.

\subsection{Decoloration by nanodendritic Au}

Figure 5(a) shows the SEM image of nanodendritic Au fabricated by SWPP electrolysis. Needle-like dendritic structures with thickness below $80 \mathrm{~nm}$ were obtained. The nanodendrite arms showed clear facets and edges, in good contrast to the smooth surface of nanoporous Au fabricated by dealloying for comparison (Fig. 5(b)). ${ }^{12)}$ Figure 6 shows the $\mathrm{CV}$ curves for the nanodendritic Au. Adsorption and desorption of oxygen at the Au surface was clearly observed as an anodic peak around $+1.0 \mathrm{~V}$ and cathodic peak around $+0.6 \mathrm{~V}$, respectively. The roughness factor calculated from eq. (1) was 20.

Figure 7 shows the time variation of reacted methyl orange (in nmol, normalized by true surface area) of nanodendritic and nanoporous Au. Considering that the vertical axis in Fig. 7 is normalized by true surface area, one can conclude that methyl orange reacted more efficiently at the surface of nanodendritic $\mathrm{Au}$ than by nanoporous $\mathrm{Au}$. The decoloration observed here is different from that caused by photocatalysis 


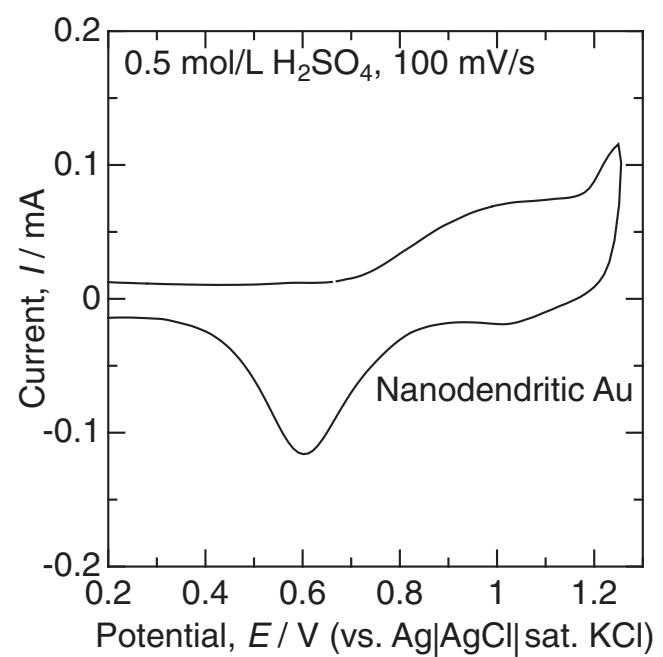

Fig. 6 Cyclic voltammetry curves for nanodendritic Au.

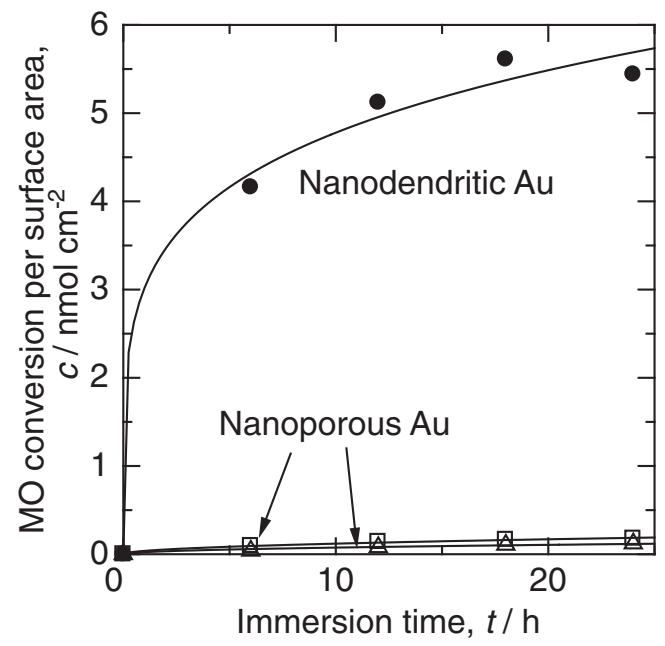

Fig. 7 Time variation of reacted methyl orange (MO) normalized by active surface area of nanodendritic and nanoporous $\mathrm{Au}$.

in semiconductive oxides such as $\mathrm{TiO}_{2}$ and $\mathrm{ZnO}$ because the immersion was conducted under a dark condition.

An additional set of experiments was conducted to confirm the catalytic decomposition of methyl orange. Figure 8 shows the UV-Vis spectra of the methyl orange solution before and after 240-h immersion of nanodendritic Au. After the immersion, the absorbance at the visible light wavelength range $(400-700 \mathrm{~nm})$ decreased, which corresponds with the decoloration of the methyl orange solution. However, the absorbance in an ultraviolet region of $\lambda<220 \mathrm{~nm}$ remained unchanged after the immersion. The absorbance of the azo dye solution in the ultraviolet region is closely related to a short conjugated system of the organic molecule and typical of phenyl rings, while that in the visible light wavelength range is caused by azo group $(-\mathrm{N}=\mathrm{N}-) .{ }^{13)}$ Methyl orange contains two phenyl rings bridged by an azo group in its chemical structure; therefore it is surmised that methyl orange decomposed to single phenyl ring compounds in the presence of nanodendritic Au.

The result shown in Fig. 8 demonstrates that nanodenditic $\mathrm{Au}$ can catalytically reduce the MO concentration by chemical decomposition of methyl orange and not by the

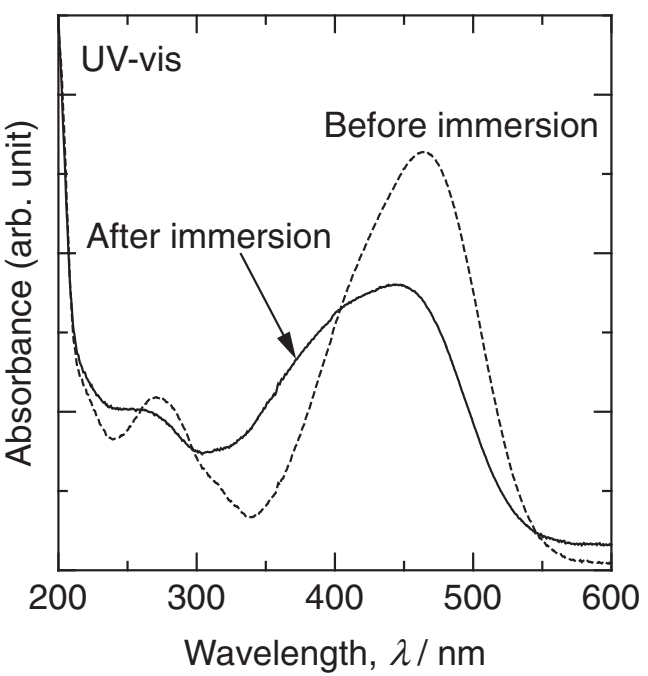

Fig. 8 UV-Vis spectra of methyl orange solution before and after 240-h immersion of nanodendritic $\mathrm{Au}$ at room temperature.

simple adsorption of MO on the surface of the nanoporous $\mathrm{Au}$, such as reported in the case of mesoporous iron oxides. ${ }^{14)}$

As shown in Fig. 7, nanodendritic Au decomposed methyl orange more efficiently than nanoporous Au. Several studies have shown that SWPP and other techniques can create high-index facets on the noble-metallic nanostructure. For example, Tian et al. reported the synthesis of tetrahexahedral Pt nanocrystals with high-index facets and subsequent high electro-oxidation activity. ${ }^{15)} \mathrm{Xia}$ et al. also reported the enhancement in electrocatalytic properties of Pt nanoframes due to high-index facets therein. ${ }^{16)}$ High-index facets are also observed in Pd nanostructure and offers enhanced electrochemical oxidation capacities. ${ }^{17,18)}$ The present nanodendritic $\mathrm{Au}$ also has clear facets and edges, as shown in Fig. 5(a). Considering these, one can suppose that the present nanodendritic $\mathrm{Au}$ may possess high-index facets, possibly resulting in the enhanced catalytic decomposition of methyl orange, although the decomposition of methyl orange is different from electrochemical oxidation seen in those literatures. $^{15-18)}$

\section{Summary}

Nanodendritic $\mathrm{Pd}$ and $\mathrm{Au}$ were fabricated by SWPP electrolysis. The nanodendritic surface structures, which have dendrite cell sizes well below $50 \mathrm{~nm}$, increase the actual surface area of Pd by up to 57 times. Catalytic decoloration capacity of nanodendrite $\mathrm{Au}$ is better than that of nanoporous $\mathrm{Au}$, possibly because of its high proportion of high-index facets and edges.

\section{Acknowledgments}

M. H. thanks JFE 21st Century Foundation for the financial aid for the fabrication and decoloration capacity evaluation of nanodendritic Au. The synthesis of nanoporous $\mathrm{Au}$ was also supported financially by a JSPS Grant-in-Aid for Young Scientists (B) 24760572. The authors also thank Prof. T. Yao and Prof. T. Yabutsuka (Kyoto Univ.) for the cooperation of SEM observations. 


\section{REFERENCES}

1) M. Haruta, N. Yamada, T. Kobayashi and S. Iijima: J. Catal. 115 (1989) 301-309.

2) A. I. Yanson, G. Rubio Bollinger, H. E. van den Brom, N. Agraït and J. M. van Ruitenbeek: Nature 395 (1998) 783-785.

3) Z.-Q. Tian, B. Ren and D.-Y. Wu: J. Phys. Chem. B 106 (2002) 9463 9483.

4) G. R. Bamwenda, S. Tsubota, T. Nakamura and M. Haruta: Catal. Lett. 44 (1997) 83.

5) Y. Xia, J. Liu, W. Huang and Z. Li: Electrochim. Acta 70 (2012) 304 312

6) Y.-J. Chen, S.-G. Sun, S.-P. Chen, J.-T. Li and H. Gong: Langmuir 20 (2004) 9920-9925.

7) Z. Zheng, S. Tang, S. Vongehr and Z. Meng: Mater. Chem. Phys. 129 (2011) 594-598.

8) H. Qiu, L. Lu, L. Xue and X. Huang: Electrochim. Acta 55 (2010) 6081-6087.

9) S. Trasatti and O. A. Petrii: J. Electroanal. Chem. 327 (1992) 353-376.
10) C. W. Yen, M. A. Mahmoud and M. A. El-Sayed: J. Phys. Chem. A 113 (2009) 4340-4345.

11) I. M. Arabatzis, T. Stergiopoulos, D. Andreeva, S. Kitova, S. G. Neophytides and P. Falaras, J. Catal. 220 (2003) 127-135.

12) M. Hakamada, F. Hirashima and M. Mabuchi: Catal. Sci. Technol. 2 (2012) 1814-1817

13) M. J. K. Thomas: Ultraviolet and Visible Spectroscopy, Analytical Chemistry by Open Learning, 2nd ed., (John Wiley \& Sons, Ltd., Chichester, UK, 1997), Chap. 5.

14) S. Asuha, Y. W. Gao, W. Deligeer, M. Yu, B. Suyala and S. Zhao: J. Porous Mater. 18 (2011) 581-587.

15) N. Tian, Z.-Y. Zhou, S.-G. Sun, Y. Ding and Z. L. Wang: Science 316 (2007) 732-735.

16) B. Y. Xia, H. B. Wu, X. Wang and X. W. Lou: Angew. Chem. Int. Ed. (in press. doi:10.1002/anie.201307518).

17) N. Tian, Z.-Y. Zhou and S.-G. Sun: Chem. Commun. (2009) 15021504.

18) N. Tian, Z.-Y. Zhou, N.-F. Yu, L.-Y. Wang and S.-G. Sun: J. Am. Chem. Soc. 132 (2010) 7580-7581. 